\title{
06 | Factores de progreso en la vivienda subvencionada madrileña de los años cincuenta. Reseña histórica y normativa _Juan Manuel Ros García
}

\section{Reseñas históricas. Instrumentos de desarrollo}

Desde que, en agosto de 1924, Luis Lacasa hace mención escrita del libro publicado por Hermann Muthesius sobre Casas Baratas - Kleinhaus und Kleinsiedlung ,1922-, presentando por primera vez cuestiones constructivas al problema de racionalización de viviendas en España y proponiendo dar forma a la construcción con un sentido realmente coherente desde criterios de normalización ${ }^{1}$, las distintas y conocidas fórmulas de gestión de los Poblados Dirigidos y de Absorción, las Unidades Vecinales, las Unidades Residenciales, así como Concursos de Viviendas Experimentales en Madrid, encaminados a crear campos de experimentación real en la segunda mitad del siglo XX, descubrirían ingeniosas soluciones a favor de la calidad de la vivienda económica, siempre al mínimo coste posible y abriendo una línea a la modernidad.

Para alcanzar, al menos en parte, los resultados deseados, fue determinante, además, una adecuada coordinación entre los distintos organismos institucionales (Instituto Nacional de la Vivienda-INV, Obra Sindical del Hogar-OSH, y la Comisaría de Ordenación Urbana de Madrid-COUM) y la existencia de un marco normativo adaptado - Ley de Viviendas de Renta Limitada-2 a las exigencias concretas de un nuevo modelo constructivo posible de vivienda social [1] [2].

Hay que referirse, en primer lugar, como antecedente, a la "vivienda de renta media" impulsada por la Ley de Viviendas Bonificables aparecida en 1944 y a las medidas de exenciones fiscales para sociedades inmobiliarias de la Ley de Reforma Tributaria, que la consideraron objeto preferente de gestión para la solución del acuciante problema de dotaciones residenciales y que, progresivamente, se convertiría en medio de cooperación entre las administraciones públicas y las empresas privadas conforme fuera terminando la década de los cincuenta. Sociedades de gestión como la Inmobiliaria San Diego, CEYSA, Banús Hermanos o Urbis, creadas en torno a 1946, acometieron grandes actuaciones empresariales de promoción en torno a los sistemas de urbanización y construcción propios de edificios para clases medias. Destaca la construcción de sectores como
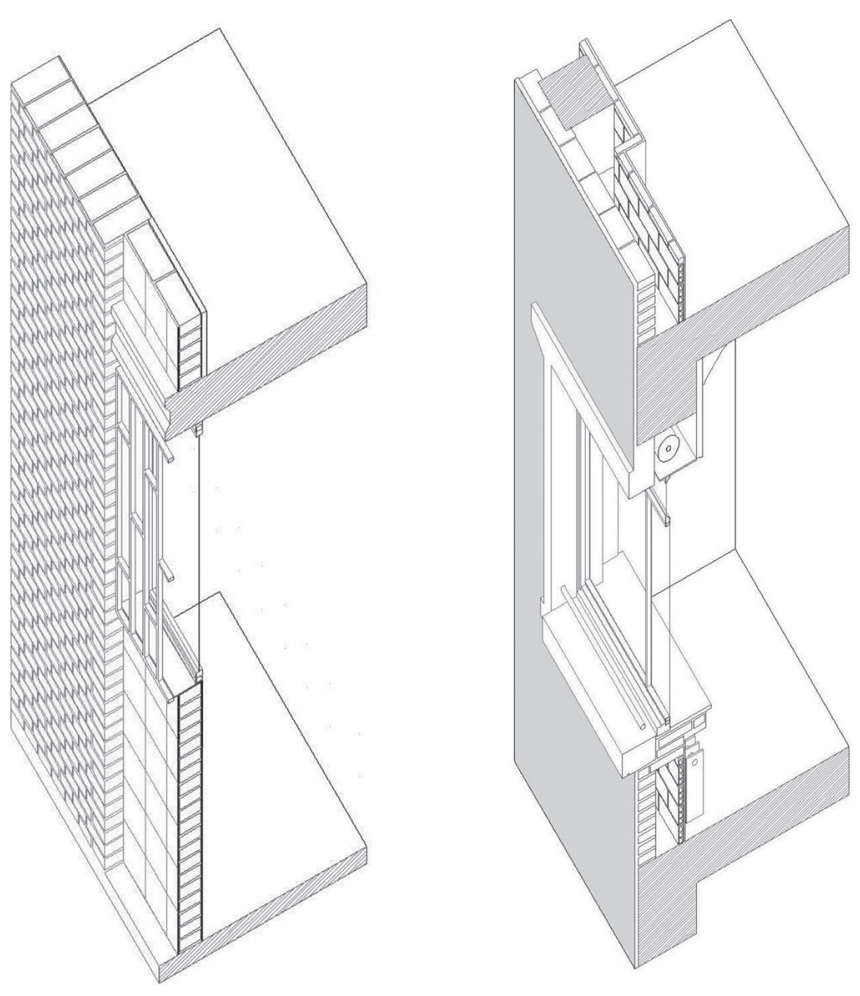

[1]

[3]
Resumen pág 44 | Bibliografía pág 50

Profesor coordinador de la Escuela Politécnica Superior Universidad CEU San Pablo -Departamento Arquitectura y Diseño- en el Área de Proyectos Arquitectónicos. Doctor Arquitecto (UPM). Investigador Principal del Grupo Rebirth.Inhabit relacionado con la vivienda social de emergencia y propuestas constructivas hacia modelos biosaludables. XVIII Premio Ángel Herrera a la Investigación en la modalidad de Arquitectura. Director del Taller de Innovación Arquitectónica-EPS. Experto en Tecnología y Construcción Arquitectónica aplicada.

\section{Palabras clave}

Vivienda social, habitabilidad, modernidad, normativa, cerramiento, historia, Madrid

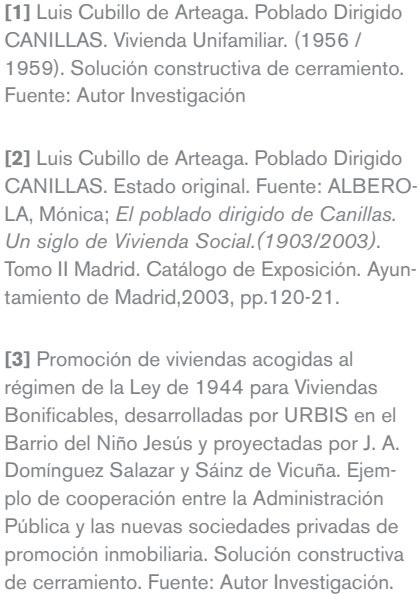

de Arteaga. Poblado Dirigido 1959). Solución constructiva de cerramiento.

[2] Luis Cubillo de Arteaga Poblado Dirigido CANILLAS. Estado original. Fuente: ALBERO Un siglo de Vivienda Social.(1903/2003). Tomo II Madrid. Catálogo de Exposición. Ayun[3] Promoción de viviendas acogidas a régimen de la Ley de 1944 para Viviendas Bonificables, desarrolladas por URBIS en el Barrio del Niño Jesús y proyectadas por J. A. ominguez Salazar y Sánz de Vicuña. EjemPública y las nuevas sociedades privadas de de cerramiento. Fuente: Autor Investigación. 


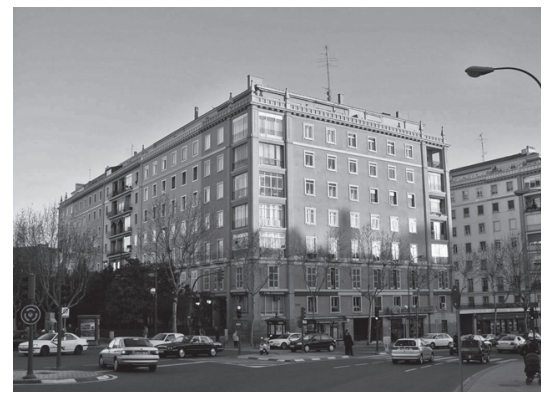

[4]

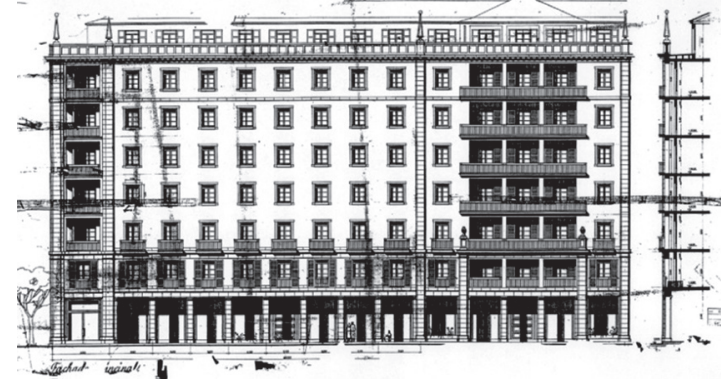

[5]
[4] J. A. Dominguez Salazar y Sáinz de Vicuña, promoción de viviendas en el Barrio del Niño Jesús. Estado actual. Fuente: Autor Investigación.

[5] J.A. Domínguez Salazar y Sáinz de Vicuña promoción de viviendas en el Barrio del Niño Jesús. Proyecto original. Fuente: DOMINGUEZ SALAZAR, J.A.; "Barrio del Niño Jesús. Inmobiliaria Urbis S.A." Arquitectura $n^{\circ} 8$ Agosto 1959. pp.29-33.

[6] 596 viviendas Grupo Marcelo Usera. Arquitecto: R. Aburto, 1956. Obra Sindical del Hogar. Proyecto presentado, junto con el Poblado de Absorción Fuencarral A de Sáenz de Oiza (1955), en la Exposición Internaciona INTERBAU de 1957 celebrada en Berlín bajo el lema "La Ciudad del Mañana", soluciones para coordinar unas viviendas subvencionadas más sanas y apropiadas. Tipológicamente

1 "Merece también especial mención el capítulo "Los tipos en la construcción", el cual encierra ideas que aun en la misma Alemania no se han desarrollado todavia, pero que hacen vislumbrar un porvenir no muy lejano en el cual la construcción ha de tomar nuevos caminos" LACASA, Luis; Un libro alemán sobre casas baratas, Arquitectura, añoVI, $n^{\circ} 64$, agosto 1924, pp. 231-236.

${ }^{2}$ Asi, por ejemplo, el Plan Sindical de la Vivienda para los años 1954-1955, que contemplaba la construcción de 55.000 viviendas para miembros de los sindicatos -que para el caso de Madrid tenía programada la construcción de algo más de 9.000 viviendas repartidas en 15 grupos residenciales-, fija los criterios según las distintas categorias de viviendas: de renta reducida y de renta mínima. Según este criterio normativo de viviendas de renta limitada se inscribian, entre otros, el Grupo de Garcia Noblejas, el Grupo Usera ver ([2]) el Grupo La Elipa, Grupo San Blas, Grupo San Fermin, Grupo Juan Tornero, Grupo Vallecas y Grupo Comillas.

${ }^{3}$ SÁENZ DE OIZA, F.J.; Sesión de crítica de arquitectura, Revista Nacional de Arquitectura, $n^{\circ} 193$, añoXVIII, enero 1958, p.36. el de Palomeras Altas -710 viviendas, urbanizadora San Diego-, en Ricardo Ortiz -960 viviendas, urbanizadora CEYSA-, en el arroyo del Calero, el barrio de la Concepción -2.856 viviendas, urbanizadora Banús-, la ampliación de la avenida del General Mola -actual Príncipe de Vergara, Grupo Torras- y, especialmente para Urbis, la urbanización y ordenación de vivienda bonificable en el barrio del Niño Jesús proyectada en 1946 por los arquitectos Domínguez Salazar y Sáinz de Vicuña, realizada solo una parte de las 2.000 viviendas contempladas. [3] [4] [5]

Resultó sin duda interesante, pocos años más tarde, dar a conocer el repertorio de las diferentes plantas de viviendas expuestas y publicadas en 1951 con motivo de la Exposición Constructa-Bauausstellung celebrada en Hannover por la Asociación Alemana de Arquitectos. En ella claramente se propone el modelo de la investigación sobre nuevos materiales y estandarización constructiva, mediante la prefabricación industrial, para obtener criterios objetivos de clasificación y racionalización de los tipos de vivienda y su arquitectura más idónea. Igualmente, en el verano de 1957 se celebraría en Berlín la Exposición Internacional Interbau con el tema principal de la nueva construcción presente en la edificación de viviendas en toda Europa y con la construcción del Barrio Hansa como elemento principal. Se proyectan los edificios del nuevo barrio con una variada tipología y disposición, a cargo de cincuenta arquitectos seleccionados de todo el mundo, con el objeto de investigar sobre los modelos de vivienda subvencionada. Se completa el encuentro internacional con un pabellón en el que se celebra la exposición, bajo el lema "La Ciudad del Mañana", en la que se presentan los problemas y soluciones para coordinar urbanismo, arquitectura y una idea de vivienda más sana y agradable. La representación española en el certamen fue presentada en un pabellón próximo al de "La Ciudad del Mañana", dedicado exclusivamente al tema de la vivienda, exponiendo la gestión llevada a cabo por la Obra Sindical del Hogar. Concretamente, destacan en la exposición, entre otras, las obras del Poblado de Absorción Fuencarral A de F. J. Sáenz de Oiza,1955, y las viviendas del Barrio de Usera de R. Aburto,1956, con las que se pretende manifestar los buenos resultados conseguidos con el marco legislativo existente [6]. Sáenz de Oiza, al referirse a la experiencia del Barrio Hansa en la Interbau de Berlín, comenta de manera resignada: "Por otra parte, nuestro nivel en el arte o en la industria del construir es bajo y no podemos hacer esos edificios que exigen una terminación y un acabado perfecto. Así, nuestros resultados dejan bastante que desear"3.

La finalidad de los núcleos satélites de agrupaciones de viviendas, o Poblados de Absorción y Mínimos, situados en un marco amplio territorial, era eliminar el chabolismo, las chozas o las cuevas de determinados lugares de la ciudad, para liberar suelo de crecimiento urbano y, así,

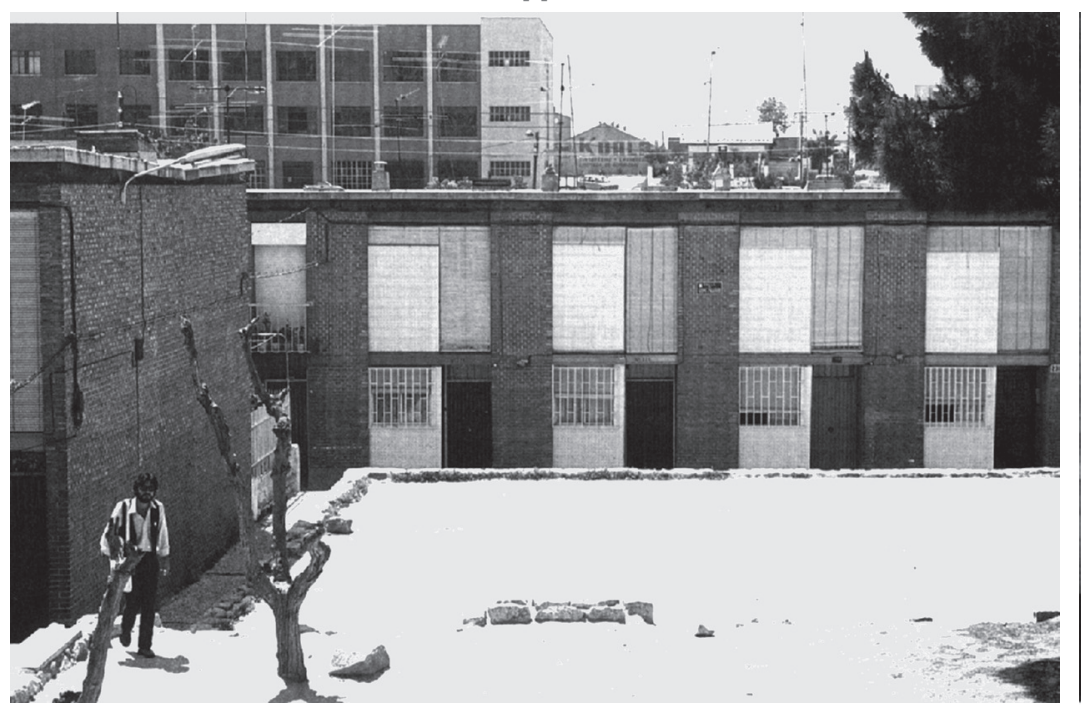

$[6]$

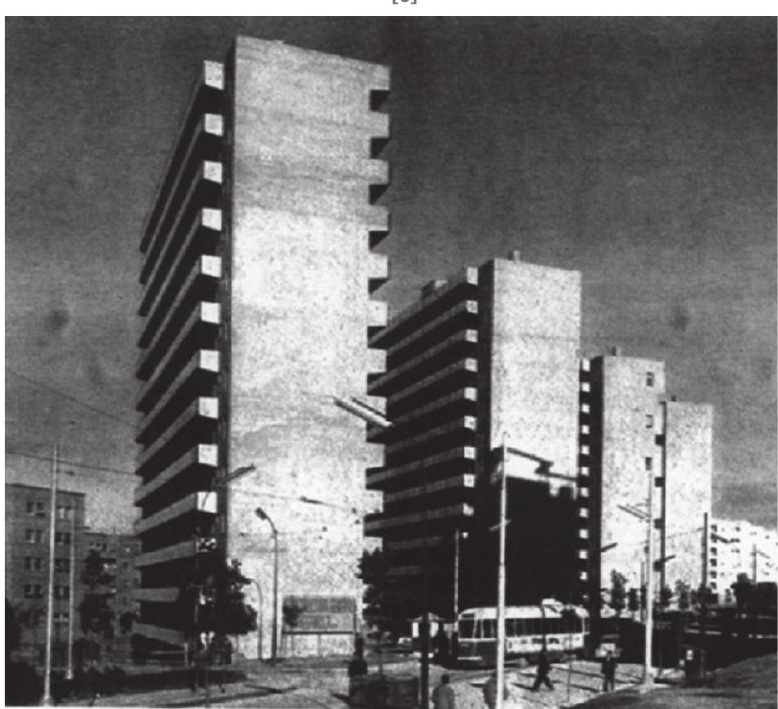




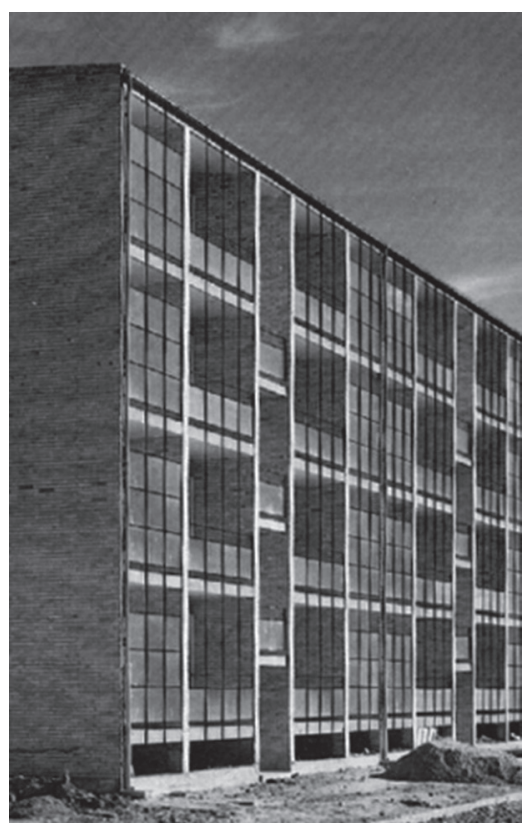

[7]

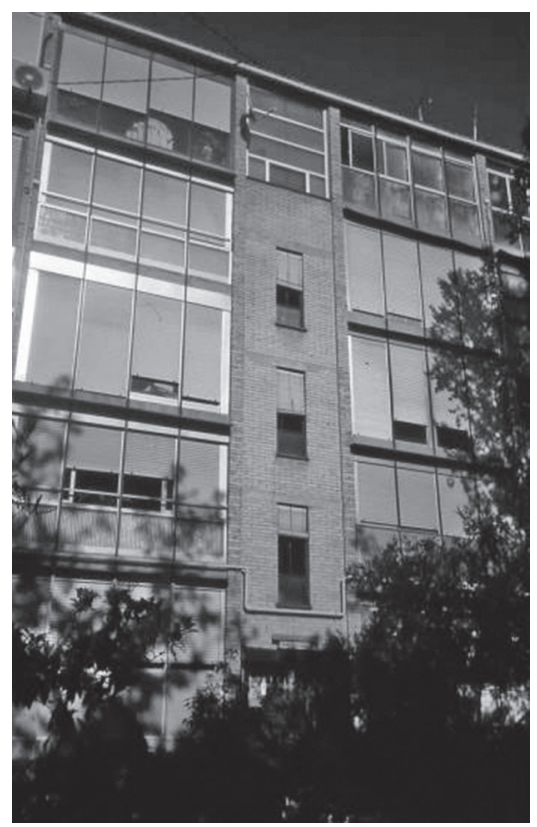

[8]

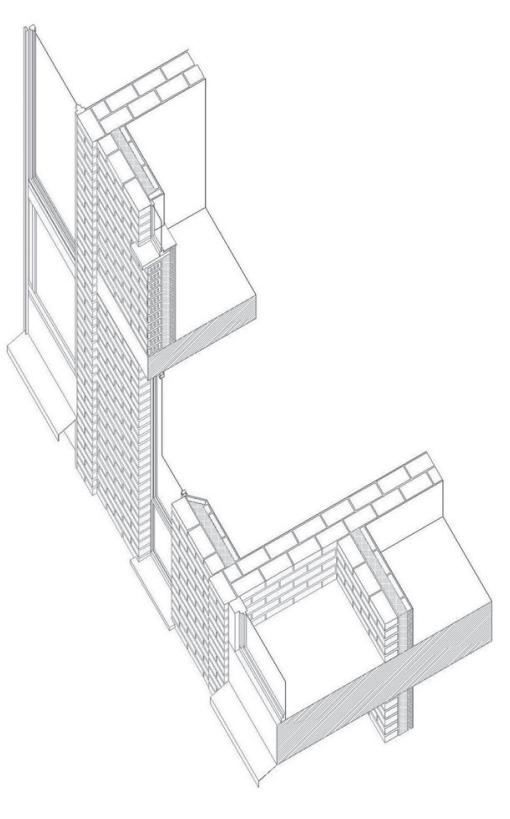

[9]

trasladar con urgencia a los aproximadamente 120.000 habitantes de esas áreas de infraviviendas a colonias de nueva creación y de bajo presupuesto, a base del tipo de vivienda "social" de rango inferior y $42 \mathrm{~m}^{2}$ de superficie máxima a la que accederían en régimen de alquiler. Los llamados Poblados Dirigidos de renta limitada, que ocuparian en gran parte las zonas liberadas por los anteriores chabolistas, surgen por decreto del 8 de marzo de 1957 y se concibieron para los emigrantes recién llegados a la ciudad. Tenían como fin contemplar que los futuros inquilinos colaborasen en la compra de materiales de construcción que se les suministraban o que participaran directamente en la ejecución de sus viviendas, a las que accederían en propiedad, bajo el control del arquitecto director de obra y mediante la denominada prestación personal por el 20\% del valor de la vivienda. El marco legislativo se corresponde con la Ley de 1954 de Viviendas de Renta Limitada, Régimen de Protección, Grupo II. "Estos poblados se hacen con aportaciones de los particulares, bien en metálico o bien con su trabajo personal, de modo que el esfuerzo conjunto del Estado y del particular colabore a la resolución del problema de la vivienda de las clases modestas"4. [7] [8] [9]

Antes de que en 1954 Julián Laguna asumiera el cargo de comisario de la COUM, en 1950 se plantea proponer un Plan a cinco años para la construcción de 30.000 viviendas, así se plantearon los Poblados de Absorción -cuya construcción correrá a cargo de la OSH- de Manoteras, Canillas, San Blas, Palomeras y Villaverde. Más tarde, en 1953, vinieron los de Peñagrande, Vicálvaro y Carabanchel. El orden y proceso de ejecución de cada uno de ellos sufrió alteraciones con relación a las condiciones en sus propuestas iniciales, siendo el núcleo de San Blas el primero en comenzarse. Recogieron las influencias transmitidas por el clima de aperturismo internacional a los modelos neoconstructivos de viviendas como el analizado por la exposición Constructa de Hannover en 1951, aunque los elevados costes de producción obligaron a retomar los modelos de casas-patio unifamiliares de dos alturas con los criterios más tradicionales de economía conocida para la pura experiencia arquitectónica. Bajo un aspecto de construcción material, los Poblados de Absorción y, con más razón, los Poblados Mínimos (concebidos como alojamiento temporal, como el de Orcasitas o el de Vallecas (1958), aunque deberían necesariamente cumplir con las Ordenanzas Técnicas y Normas Constructivas aprobadas en 1955 desde la $\mathrm{OSH}$, no se basaron nunca en una gran experimentación técnica de recursos materiales, sino en soluciones de la máxima simplicidad constructiva, con especial tratamiento y cuidado por la

[10]

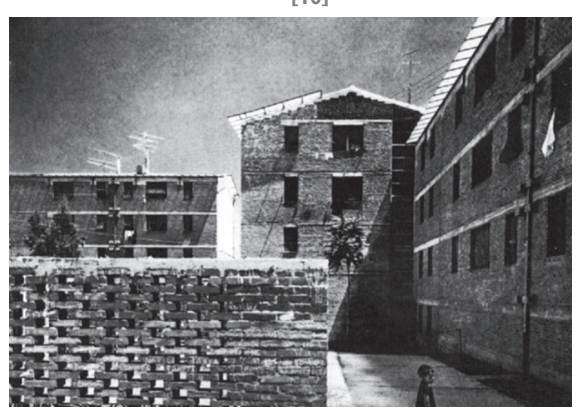

[11]

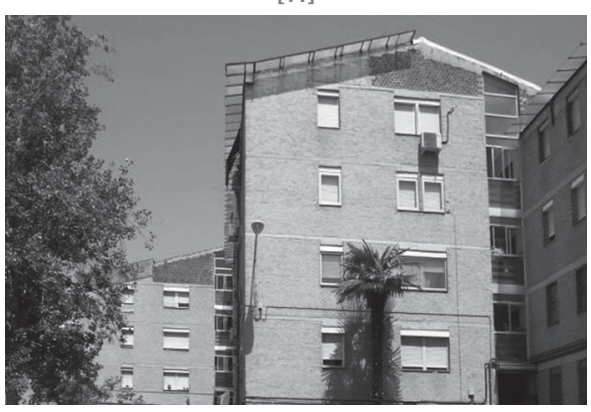

se abandona la solución de patio cerrado, prohibido por la normativa, para desarrollar otra de viviendas corredor en la orientación más adecuada del bloque abierto. Estado original. Fuente: Hogar y Arquitectura. № 28. Mayo-Junio 1960, pp. 19-31.

[7] José Luis Romany Aranda. Poblado Dirigido FUENCARRAL. Bloque, Fachada Sur. 1958 / 1960 Estado original. Fuente: AA.VV. La quimera moderna. Los Poblados Dirigi dos de Madrid en la arquitectura de los 50. Madrid: Ed.Hermann Blume, 1989.

[8] José Luis Romany Aranda. Poblado Dirigido FUENCARRAL. Bloque, Fachada Sur. 1958 / 1960 Estado actual. Fuente: Autor Investigación.

[9] José Luis Romany Aranda. Poblado Dirigido FUENCARRAL. Solución constructiva de cerramiento. Fuente: Autor Investigación.

[10] F.J.Sáenz de Oíza, J.L.Romany, E. Mangada y C. Ferrán. Unidad Residencial Loyola. Estado original. Construido por la entidad Hogar del Empleado en Carabanchel.1959 Fuente: Hogar y Arquitectura n59, Julio-Agosto 1965 , pp. $20-29$.
4 "Los terrenos urbanizados, los proyectos, la dirección técnica, el suministro de materiales, la organización de la construcción y la financiación corren a cargo de los organismos oficiales y los particulares, por su parte, han de pagar los terrenos, los honorarios de proyecto y dirección y una pequeña parte de los materiales de construcción y de la mano de obra, con la modalidad de que aportando el trabajo, únicamente se pagan los terrenos y los gastos generales". "Poblado Dirigido de Caño Roto", Arquitectura, año 1, agosto $1959, n^{\circ} 8$, pp. $2-17$. 
[11] F.J.Sáenz de Oíza, J.L.Romany, E. Mangada y C.Ferrán. Unidad Residencial Loyola. Estado actual. Fuente: Autor de la Investigación.

[12] F.J.Carvajal. Viviendas Subvencionadas. Colonia de El Salvador. Ciudad Lineal. 195862 Proyecto original. Fuente: Arquitectura, año 4, nº3, Julio 1962, pp 19-23.

[13] F.J.Carvajal. Viviendas Subvencionadas. Colonia de El Salvador. Ciudad Lineal. 1958-62 Estado actual. Fuente: Autor de la Investigación.

[14] M.Fisac. Proyecto de Viviendas subvencionadas. 1955. Poblado de Absorción Zofío de Carabanchel. Estado actual. Fuente: Autor de la Investigación.

[15] M.Fisac. Proyecto de Viviendas subvencionadas. 1955. Poblado de Absorción Zofío de Carabanchel. Planta vivienda tipo $41 \mathrm{~m}^{2}$. Proyecto original. Fuente: Archivo Histórico-Fundación Cultural COAM. En donde desarrolla la solución del concurso de 1949 . Muros de ladrillo transversales de carga que permiten la libre adaptación a la topografia y la correcta iluminación y ventilación cruzada en el concepto más digno e higiénico de vivienda social.

[16] M.Fisac. Modelo de Viviendas en Cadena. 1949. "Primer premio en el concurso de proyectos de viviendas para renta reducida, convocado por el Colegio de Arquitectos de Madrid." Proyecto original. Fuente: Archivo Histórico-Fundación Cultural COAM.

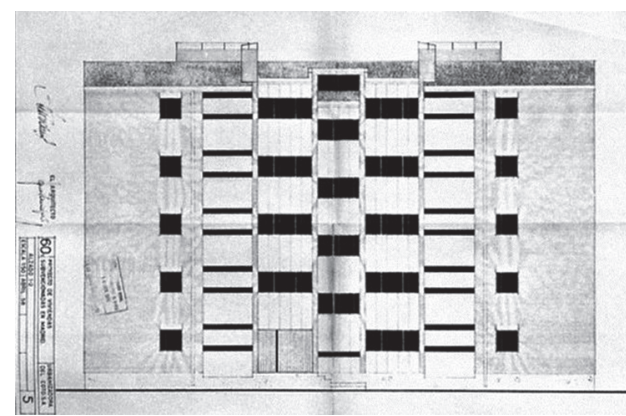

[12]

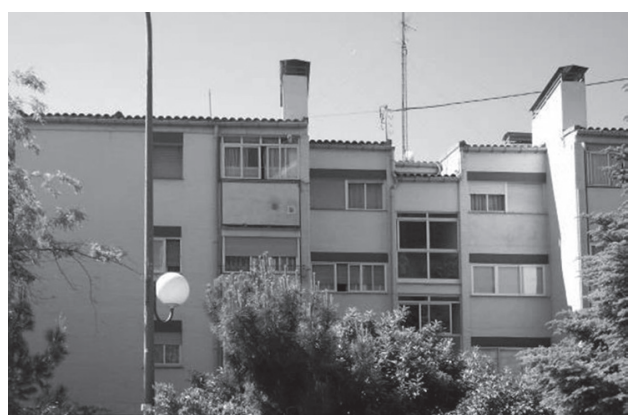

[13]

definición de las instalaciones -especialmente en los Dirigidos, como el de Entrevías de Sáenz de Oiza, Sierra y Alvear (1958)-, demostrando el interés por los aspectos relacionados con la salubridad o el confort ambiental. En este ejemplo queda patente la intención del arquitecto por la normalización constructiva como razón del proyecto. A este mismo tipo pertenece también la Unidad Residencial Loyola -Sáenz de Oiza, J. L. Romany, E. Mangada y C. Ferrán, 1957- [10] [11], los edificios para 2.074 viviendas del Gran San Blas -L. Gutiérrez Soto, J. A. Corrales, Cano Lasso y Vázquez Molezún, 1957-5, o las viviendas subvencionadas del Barrio del Salvador en la c/ General Aranaz de Ciudad Lineal -Javier Carvajal- [12] [13]. Estos planteamientos tuvieron también soporte teórico, como el artículo publicado por Fisac en la Revista Nacional de Arquitectura -"Viviendas en cadena", 1954- [14] [15] [16] con ocasión de su grupo experimental de Villaverde, promovido desde el INV y la OSH, en el que se buscan nuevas soluciones originales para vivienda protegida y materiales experimentales de aplicación.

En 195, la Constructora Benéfica Hogar del Empleado alcanzará funciones de total gestión en la mejora de las condiciones de vida de sus asociados, llegando a construir un número de 6.000 viviendas en Madrid con relativo mayor nivel de calidad que las promociones de similar categoría que se encontraban desarrollando. En muchos casos, los criterios en el planteamiento general de sus agrupaciones asentaron las bases que inspirarian actuaciones ambiciosas inmediatamente posteriores, como los comentados Poblados Dirigidos. Uno de estos ejemplos, en los que, además, se ensaya el control de todo el proceso constructivo, sería la Unidad Vecinal Batán para 752 viviendas protegidas -F.J. Sáenz de Oiza, J.L. Romany y Manuel Sierra Nava, $1955-63-^{6} \cdot[17][18][19]$

Una primera tentativa de avanzar sobre los modelos y soluciones a la cuestión de exigencia de vivienda social corresponde a la iniciativa abordada desde el Instituto Nacional de la Vivienda y la Obra Sindical del Hogar ajustándose a lo que determinaba la ley de 15 de Julio de 1954 para la construcción de 20.000 viviendas "ultrabaratas" en un año. A tal efecto se dispone la convocatoria de un concurso de viviendas experimentales a realizar en determinadas parcelas de Villaverde. El encargo del proyecto se realiza a los arquitectos Núñez Mera, Zuazo Bengoa, Fisac y

[14]

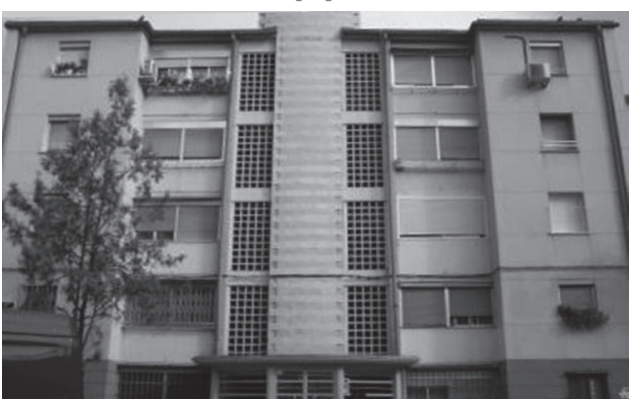

[15]

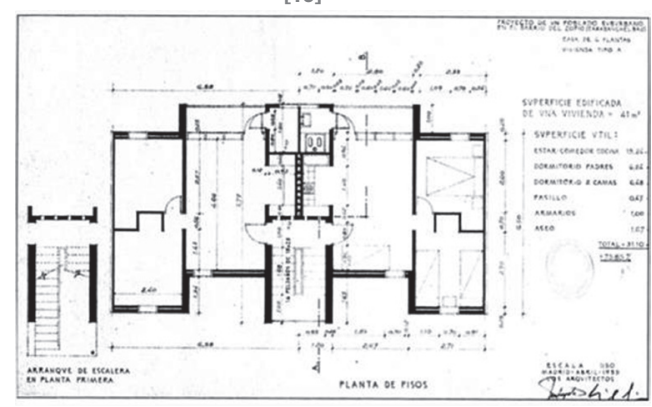

[16]

$\mathbf{5}$ GUTIÉRREZ SOTO, Luis; "Gran San Blas, parcela G.", Arquitectura, año 1, agosto 1959 $\mathrm{n}^{\circ}$ 8, pp 2-17.

${ }^{6}$ SÁENZ DE OIZA, F.J., ROMANY ARANDA, J.L. y SIERRA NAVA, Manuel; “Unidad Vecin Batán". Hogar y Arquitectura, $n^{\circ} 33$, marzo-abril 1960, pp. 2-10.

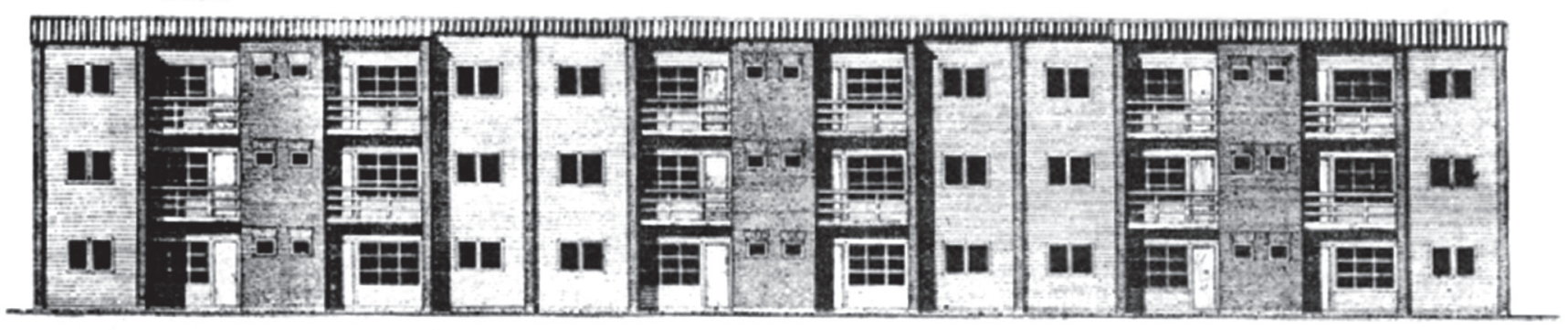




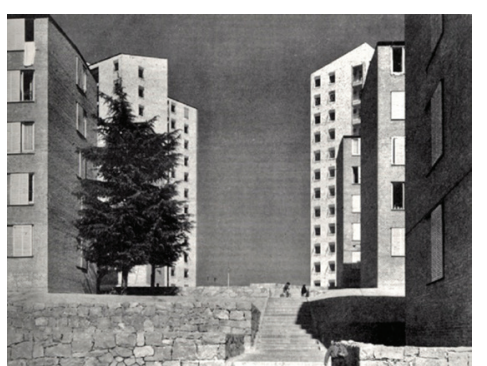

[17]

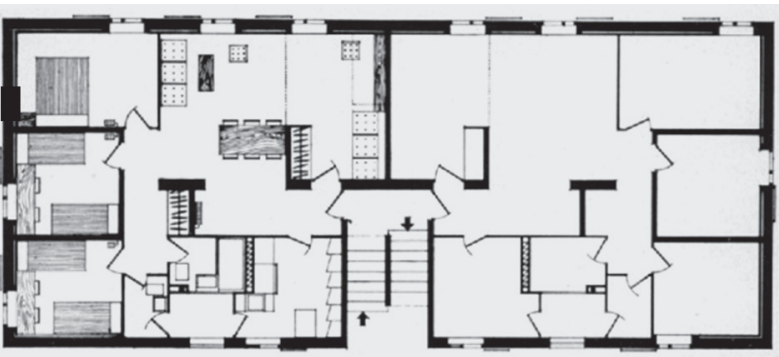

$[18]$

Carlos de Miguel. El conjunto se llevó a cabo en la Colonia San Carlos con 408 viviendas.[20] [21]

El carácter experimental se redujo, no obstante, a la aplicación ingeniosa de soluciones de siempre, eso sí, con los criterios más exigentes de racionalidad.

Así, en diciembre de 1955, en su primera fase, y en abril de 1956, en su segunda, para fomentar de nuevo la investigación sobre modelos alternativos, dentro del campo de la vivienda modesta, desde el Instituto Nacional de la Vivienda (INV), dependiente del Ministerio de Trabajo, y, como efecto del recién aprobado Reglamento de la Ley de Vivienda de Renta Limitada -BOE 16 de julio de 1955, en el que se fomentaban las iniciativas de concursos para viviendas de fines sociales-, se convoca el Concurso de Viviendas Experimentales. Su objetivo era, además -aparte de realojar a los habitantes del recinto chabolista de Jaime el Conquistador [22] [23]-, ensayar nuevos sistemas de edificación según criterios de normalización y prefabricación constructiva, organización del trabajo y aprovechamiento, con los criterios de racionalidad y valor arquitectónico añadido sobre la base de un mismo proyecto y, entre todos, los agentes participantes del proceso constructivo, esto es: “...el espíritu del Instituto al convocar este concurso estaba únicamente en el deseo de aprovechar las técnicas modernas en la construcción de viviendas de poca renta"7. El concurso se planteó bajo la fórmula innovadora de arquitecto y empresa constructora con oferta económica y de tiempo, ambos asistidos por personal técnico del INV.

En cada propuesta presentada se encuentra la intención de "...aunar las necesidades de una planta funcional, las posibilidades de nuestra industria de la construcción y las exigencias estéticas de esta época. Dentro de un presupuesto reducido"8.

La importancia de este concurso reside en la enorme variedad de soluciones planteadas, que sirvieron de repertorio y experiencia pionera constructiva para posteriores actuaciones. Una de

[19]

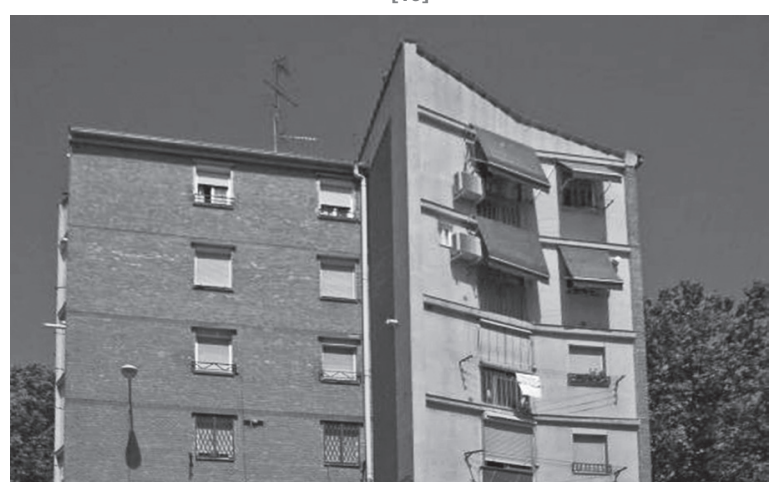

[21]

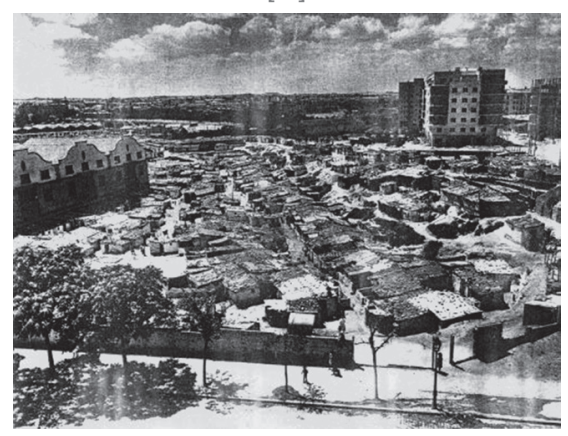

[20]

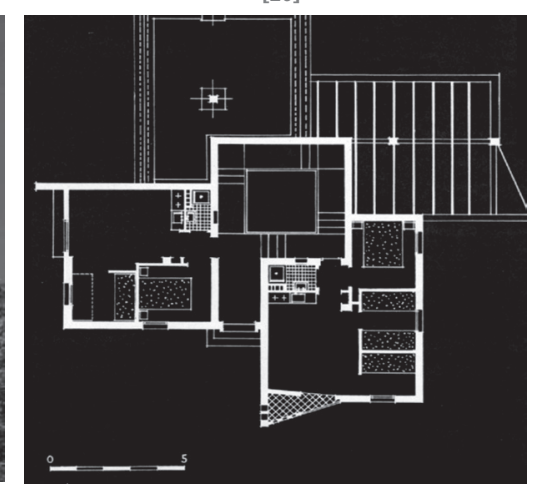

[22]

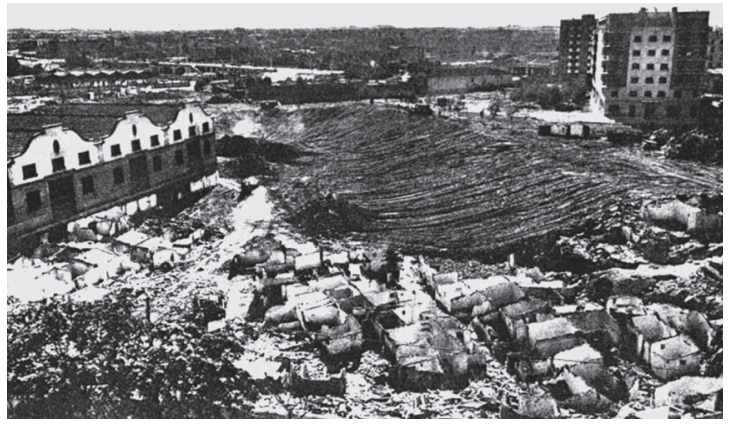

[17] F.J.Sáenz Oiza, J.L.Romany y M. Sierra. Unidad Vecinal Batán. 1955-1961.Estado roiginal. Fuente: Hogar y Arquitectura, $n^{\circ} 33$, Marzo-Abril, 1960, pp. 2-10

[18] F.J.Sáenz Oiza, J.L.Romany y M. Sierra. Unidad Vecinal Batán. 1955-1961.Proyecto Fuente: Hogar y Arquitectura, $\mathrm{n}^{\circ} 33$, Marzo-Abril, 1960, pp. 2-10.

[19] 408 Viviendas Experimentales en Villaverde. Colonia S.Carlos. 1956. Torre en Villaverde. Estado actual. Fuente: Autor de la Investigación. "La Empresa nacional que supone el Plan Nacional de la Vivienda es de todos, $y$, en primera línea, de los arquitectos españoles; éstos deben sentir hasta qué punto es necesario agudizar el ingenio, derrochar facultades, para resolver "a la española" el enorme afán de la patria para dar hogar digno y alegre a todos los compatriotas que de él carecen". Luis Valero, Director General del Instituto Nacional de la Vivienda. RNA, agosto-septiembre, $1956, n^{\circ} 176-177$, pp. 45-46.

[20] 408 Viviendas Experimentales en Villaverde. Colonia S.Carlos. 1956. Planta Tipología Torre en Villaverde. Fuente: RNA Agosto-Septiembre 1956, n ${ }^{\circ}$ 176-177, pp.45-46.

[21] Recinto chavolista Jaime I el Conquistador, Madrid. Fuente: RNA, Enero 1958 año $1^{\circ}, 193$, pp.1-12.

[22] "El recinto madrileño conocido con el nombre de Jaime I el Conquistador, verdadera lacra social, que ya ha sido demolido como se aprecia, hecha durante el desmantelamiento de las covachas. A sustituir estos cánceres urbanos tiende la labor oficial que con la colaboración de los particulares pueda dar solución al grave problema de la vivienda" RNA enero 1958 , año $1^{\circ}, 193$, pp.1-12. Fuente: RNA, Enero 1958, año1 ${ }^{\circ}$, 193, pp.1-12.

[23] Ignacio Álvarez Castelao. Edificio de viviendas. Concurso "Viviendas Experimentales" Camino Viejo de Leganés. 1956-1958. Solución constructiva de cerramiento. Fuente: Autor Investigación. "Donde esta patente centra su interés es en la forma de enlace de las distintas piezas, para lo cual, verticalmente desde los cimientos a la cubierta, una armadura auxiliar recorre el espacio que dejan entre ellos las mitades de pies derechos resistentes; horizontalmente se emplean tensores que se alojan en espacios formados por los nervios extremos de los elementos " $X$ "; estos espacios se rellenan con hormigón en la obra". Revista Nacional de Arquitectura, $n^{\circ} 195$, marzo1958, pp. 8-10. Solución constructiva. Fuente: Autor Investigación.

[24] Ignacio Álvarez Castelao. Edificio de viviendas. Camino Viejo de Leganés. 19561958 Proyecto original. Fuente: $R N A, \mathrm{n}^{\circ} 195$, Marzo1958, pp. 8-10.

[25] Ignacio Álvarez Castelao. Edificio de viviendas. Camino Viejo de Leganés. 19561958 Proyecto original. Fuente: RNA, $\mathrm{n}^{\circ} 195$ Marzo1958, pp. 8-10.

[26] Innacio Álvarez Castelao. Edificio de viviendas. Camino Viejo de Leganés. 19561958. Detalle del proyecto original. Fuente: RNA, n 195, Marzo1958, pp. 8-10.

[27] Ignacio Álvarez Castelao. Edificio de viviendas. Camino Viejo de Leganés. 19561958 Detalle del proyecto original. Fuente: RNA , n $\mathrm{n}^{\circ} 195$, Marzo1958, pp. 8-10.

[28] Ignacio Álvarez Castelao. Edificio de viviendas. Camino Viejo de Leganés. 19561958 Estado original. Fuente: RNA, $\mathrm{n}^{\circ} 195$ Marzo1958, pp. 8-10.

[29] Ignacio Álvarez Castelao. Edificio de viviendas. Camino Viejo de Leganés. 1956 1958 Estado actual. Fuente: Autor Investigación. 


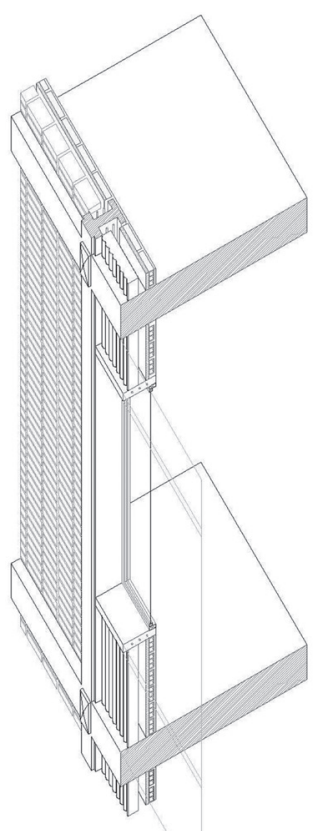

[23]
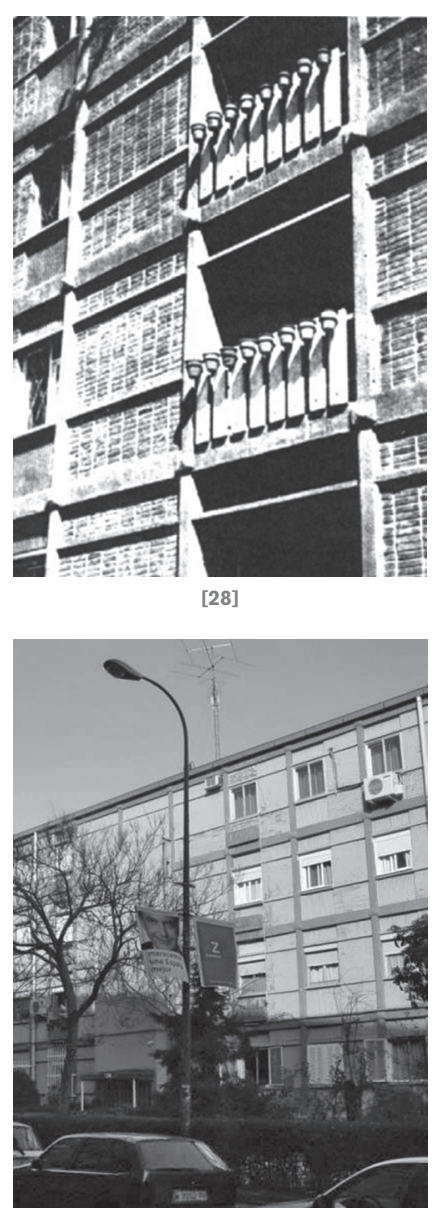

[29]

${ }^{7}$ Primer concurso de viviendas experimentales. Revista Nacional de Arquitectura, $\mathrm{n}^{\circ} 193$ febrero 1958, pp. 1-12.

${ }^{8}$ MIGUEL, Carlos de; "Viviendas subvencionadas". Arquitectura, año $1, n^{\circ} 8$, agosto 1959 , pp. 37-38.

9 ÁlVAREZ CASTELAO, Ignacio; "Viviendas experimentales". Revista Nacional de Arquitectura, año XVIII, n ${ }^{\circ} 195$, marzo 1958, pp. 8-10. 10 SÁENZ DE OIZA, Francisco Javier; "Viviendas experimentales". Arquitectura, año1, $\mathrm{n}^{\circ} 2$, febrero 1959, pp. 5-11.
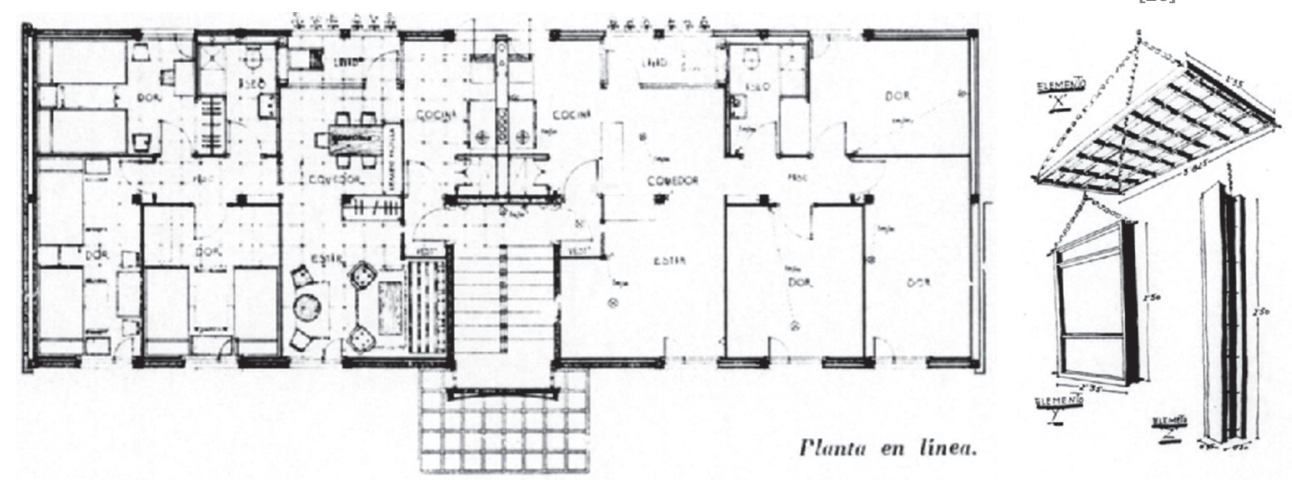

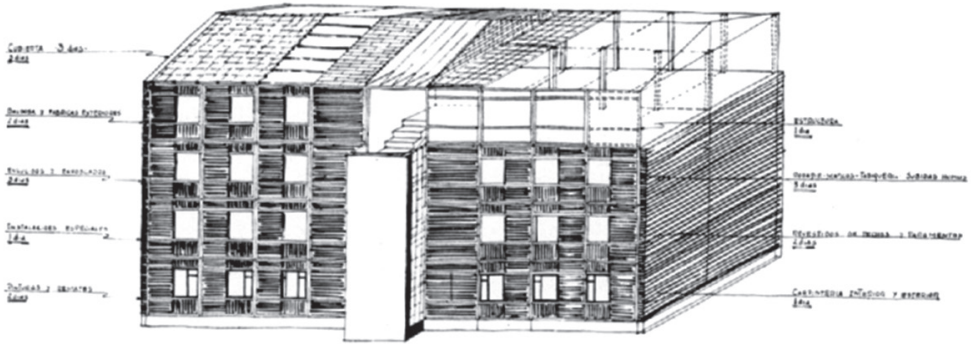

[25]

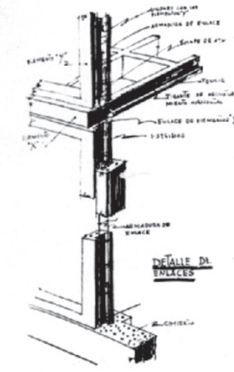

[27] las más interesantes corresponde a la del arquitecto Ignacio Álvarez Castelao. Esta solución, presentada por la empresa Constructora Asturiana S.A., contemplaba un sistema integral prefabricado, realmente novedoso, a base de módulos tipo "mit", que consistían en "Elementos X" de retículas armadas en las dos direcciones para formación de forjados sin vigas, y los "Elementos Y" de entramado vertical modulado según $35 \mathrm{~cm}$ x $35 \mathrm{~cm}$ para formación de huecos y transmisión estructural, arriostrados a su vez por piezas horizontales entre montantes principales, de manera que puedan implementarse con cierres de fábrica, en este caso con ladrillos dispuestos con llagas continuas. [24] [25] [26] [27] [28] [29] [30]

La crítica a los planteamientos de partida entendidos como demasiado elevados, llega, como otras veces, del propio Sáenz de Oiza al referirse a la realización de su proyecto presentado: "Las soluciones propuestas no suponen innovación de patentes extrañas en los tradicionales sistemas de edificar, sino mejora en la técnica de construir de aquellas partes que consideramos que son fácilmente y hasta necesariamente revisables. No somos partidarios de la creación de nuevas industrias encaminadas a resolver un determinado tipo de edificio, sistema siempre limitado y de resultado dudoso aplicado en desarrollos en masa, únicos que hacen posible su industrialización. Creemos, por el contrario, que la industrialización debe orientarse, de un lado, hacia el perfeccionamiento gradual de los tradicionales formas de edificar, y de otro, a la producción industrializada, seriada o modulada de sólo partes del edificio que, al ser producidas en gran número para su aplicación en distintos proyectos y localidades, permiten con seguridad su verdadera producción industrial". ${ }^{10}$

El concurso permitió, aparte de construir un total de 866 viviendas, generar expectativas nuevas entre los sistemas conocidos en el proceso de construcción de viviendas, sobre todo en la implantación de los métodos de prefabricación, patentes y criterios de montaje que, por otra parte, ya se extendían por la industria de otros países, pero que, aplicados en las condiciones límites de nuestro país, no llegaron sino a convertirse en aspectos avanzados destinados solo a especialistas, sin alcanzar gran repercusión social, y que se convertirian, de forma operativa y obligada, en mecanismos mixtos de adaptación local.

Se divulgan, además, en revistas especializadas, textos publicados por organismos internacionales para la conciencia y el fomento de la productividad, como The European Productivity Agency of the Organisatión for European Economic Co-operation, en los que se insiste sobre la conveniencia de adoptar "un sistema modular como base para la normalización de los componentes del edificio. La solución del problema es una serie modular de componentes en el cual el tamaño de cada uno, o los tamaños de los componentes de cualquier serie particular, son parte de un sistema coordinado de medidas"11 $y$, de esa manera, se reducen los elevados costes de construcción de viviendas con métodos tradicionales en todo el mundo ya que el "uso de un módulo internacional aumentaría las posibilidades de un comercio internacional de materiales y componentes de la construcción"12. 


\section{Reseñas normativas. Conclusión}

Así, desde que la Ley de Casas Baratas del 12 de junio de 1911 representara el primer precedente de regulación técnica de aplicación a la construcción pública de viviendas promovidas por el Estado -el siguiente texto legislativo data del 10 de diciembre de 1921-, se marcan lo que podría entenderse como niveles mínimos de calidad y habitabilidad necesarios, relacionados con posibilidades suficientes de ventilación e iluminación. De este modo, en su Art.58, y con relación a los elementos de cierre, se puede leer: "Los cimientos y muros hasta $1 \mathrm{~m}$ de altura han de construirse de modo que resulten protegidos contra la humedad del suelo... Los muros exteriores y las cubiertas deberán tener las debidas dimensiones para garantizar su solidez y habrán de proteger suficientemente el interior contra las variaciones atmosféricas de humedad y temperatura". En su Art.94 se refiere a la necesidad de emplear los conceptos básicos de sencillez constructiva a favor de la economía general del sistema y afectando a las decisiones de acabados, sabiendo que los detalles constructivos finales serían "de la iniciativa de los arquitectos y peritos que proyecten las casas, los cuales adoptarán en cada caso, los procedimientos más convenientes dentro de la economía. Ésta se obtendrá empleando fábricas y entramados de sencilla construcción y mantenimiento. Pero no ha de imponerse la economía hasta el punto de que carezca la obra de las garantías de solidez y duración compatible con la reducción razonable de los gastos de construcción y mantenimiento, ni ha de olvidarse tampoco que, para los efectos sociales, el concepto de casa barata no puede desligarse del de casa higiénica".

La legislación vigente posterior, esto es la Ley de Casas Económicas para las Clases Medias de julio de 1925, la Ley para Funcionarios del Estado de diciembre de 1927, la denominada "Ley Salmón" de 1935 y sus correspondientes reglamentos técnicos de condiciones constructivas, mantienen criterios similares a los mencionados anteriormente. Tras la guerra comienza un intenso periodo de promulgación legislativa referente a la política de construcción de vivienda, que modificaría los vigentes durante la época de la Dictadura y de la República. El texto principal daría lugar al nuevo régimen de protección "a favor de las entidades y particulares que construyan viviendas higiénicas de renta reducida" contemplado en la Ley de Protección de Vivienda del 19 de abril de 1939, acompañada de la creación del Instituto Nacional de la Vivienda que garantizaría, con su gestión, su cumplimiento. El reglamento técnico de la ley se aprueba el 18 de septiembre de 1939, y en él se tipifican las ordenanzas generales constructivas de aplicación y los modelos característicos que habrían de cumplir las viviendas protegidas bajo el amparo del Estado, que darían lugar al desarrollo de una normativa específica en la que se enmarcó la práctica generalizada de los asentamientos residenciales como respuesta al aumento de población en la ciudad. Será el Reglamento de Régimen Interior del INV del 29 de enero de 1941, aplicable a la Ley de Protección de Vivienda de 1939 y bajo la dirección de Benjumea Burin, el que definirá las condiciones mínimas para la protección considerada en el régimen legislativo. Significa, por primera vez, desde los organismos estatales y con relación a lo definido en anteriores textos normativos, un avance importante de exigencia en la precisión y cuantificación objetiva de los datos técnicos presentes en el proyecto del arquitecto. En el Capítulo I, en su apartado 4. Art.11-Sección Técnica de la Oficina Central, se fija que: "La Sección Técnica entenderá en lo relativo a las condiciones técnicas de construcción e higiénicas que han de reunir las viviendas protegidas que se construyan"13. En sus ordenanzas se destacan, asimismo, con profundidad los aspectos materiales, constructivos e higiénicos que tienen que cumplir las unidades de alojamiento para el cumplimiento de las exigencias mínimas establecidas de calidad. Establece la obligación de contemplar, fijando unos parámetros mínimos, una normativa técnica de alcance nacional para la construcción de viviendas de carácter social. En el texto, de lógica inspiración restrictiva de posguerra, se determinan datos objetivos para el análisis y comportamiento térmico de los cerramientos. Por primera vez, se deja abierta la posibilidad de proponer, siempre que sea económicamente viable, soluciones avanzadas e innovadoras para cerramientos con la condición de racionalizar su comportamiento y justificar el cumplimiento de las condiciones normativas. Este hecho influyó de manera rotunda en el carácter y desarrollo especializado de los nuevos materiales incluidos en la composición de fachadas, permitiendo, al amparo normativo, la máxima reducción de superficie construida en planta de las mismas a favor del aumento de la superficie útil, al mismo tiempo que exigió una mayor y necesaria precisión gráfica de las soluciones incorporadas en el proyecto para su aprobación una vez supervisado. Y ello ocurre en un momento de precariedad económica tras la contienda, como esfuerzo de control económico de los recursos destinados a la solución urgente de la vivienda.

Este cambio cualitativo de análisis del problema, su precisión en la definición técnica y su necesidad de aprobación, trajo consigo una nueva actitud en la experimentación de otras soluciones constructivas bajo la condición de cumplimiento de los mínimos establecidos en las ordenanzas que, sin duda, supuso una renovación arquitectónica global del modelo de vivienda bajo las premisas modernas de especialización material. La promulgación de aquel texto normativo de
11 MOYA, Luis. "Coordinación Modular" Revista Nacional de Arquitectura. $\mathrm{n}^{\circ} 187$, julio 1957, pp. 31-38

12 MOYA, Luis. op.cit.

13 Boletín Oficial del Estado, 13 febrero 1941, p. 1.015. Ministerio de Trabajo. Reglamento de Régimen interior del Instituto Nacional de la Vivienda, Orden de 29 de enero de 1941. En su capítulo XXX y por primera vez en un articulado estatal de obligado cumplimiento, se configuraban las zonas climáticas de la geografía española para justificar las necesidades térmicas de aislamiento en cad caso a incorporar en las soluciones de cerramiento de fachadas o de cubiertas, limitando valores máximos de conductividad térmica. A mismo tiempo, se fijaria la superficie máxima de huecos en fachada según los $2 / 5$ de macizo de muro.

14 En las que se obliga a la utilización, como cambio y avance técnico necesario de aplicación al carácter social de vivienda las "... cubiertas rígidas de hormigón armado, cámara de aire en los muros, forjados, instalación de sanitarios, tipología de huecos exteriores, impermeabilización de cimientos". CABRERO, Francisco de Asís; "Viviendas económicas en Madrid". Informes de la Construcción, $n^{\circ} 70$, abril, 1955.

${ }^{15}$ En relación a la vivienda social de iniciativa pública frente al determinismo individualista reflejo de la producción mercantilista urbana, denunciado por autores como López de Lucio en su obra Vivienda colectiva, espacio público y ciudad. Evolución y crisis en el diseño de tejidos residenciales 1860-2010 (2013) se debe imponer la aspiración global de construir la ciudad desde el modo de vida de los ciudadanos, desde un espacio urbano cotidiano que favorezca su condición social dentro de un contexto unitario no diferenciador. López de Lucio coincide en clasificar el Poblado Dirigido de Fuencarral, reseñado también en el presente artículo [4], como actuación destacada y ejemplar de intervención urbana a la altura de otros conjuntos europeos de calidad reconocida (Amsterdam, Viena) en los que se han superado los esquematismos racionalistas a favor de una ciudad con espacio público humanizado.

[30] T. Rodriguez, Grupo Residencial Nuestra biliaria Múgica S.A. Pertenecientes a la Ley de Viviendas Subvencionadas de 1957. Proyecto original. Fuente: Archivo Histórico-Fundación Cultural COAM.

[31] T. Rodriguez, Grupo Residencial Nuestra Señora de Begoña, 1959. Estado actual. Fuente: Autor de la Investigación. 
carácter técnico, no se planteó como hecho administrativo aislado, se le sucedió otro reglamento de similares características y obligado cumplimiento aprobado el 22 de julio de 1941, de aplicación con carácter mínimo en la construcción de viviendas sociales.

Posteriormente, en 1944 y hasta 1948 entraría en vigor la Ley de Viviendas de Clase Media que definiria la figura conocida como "casa bonificable" cuya regulación dependería de la supervisión final del INV para su aprobación, y clasificaría los tipos de vivienda en tres grupos y categorías de acuerdo a condiciones de calidad constructiva de materiales o de ejecución, niveles de exigencia técnica y funcionalidad de superficies y habitabilidad. La siguiente norma fundamental entra en vigor, con la Ley de Viviendas de Renta Limitada, el 15 de julio de 1954, con su inmediato reglamento de Ordenanzas Técnicas y Normas constructivas del 12 de julio de 1955 -participó en su redacción Francisco de Asís Cabrero, desde su puesto de arquitecto jefe de la Obra Sindical del Hogar $-{ }^{14}$, derogando todos los anteriores textos vigentes de aplicación, mejorando y completando ciertas cuestiones tratadas con ambigüedad en los existentes hasta la fecha. En el marco de esta ley se desarrollarían las actuaciones más representativas en materia de alojamiento social bajo la dirección de los organismos públicos del régimen, el INV, la OSH y la COUM -con el protagonismo de su director Julián Laguna-, como fueron los asentamientos de los Poblados Dirigidos. Introduciendo o recuperando novedades importantes en la gestión y construcción de viviendas, el concepto de "prestación personal" y el instrumento de "suministro preferente de materiales", en un momento de precariedad económica, control productivo del Estado y escasez de recursos, cobrarian un relevante y positivo interés práctico.

Finalmente, se puede concluir y afirmar que La Ley de Viviendas de Renta Limitada se convirtió en un medio reglado realmente eficaz en el desarrollo de la política de vivienda hasta la nueva aparición de la Ley de Viviendas Subvencionadas de 1957, surgida desde el recién creado Ministerio de la Vivienda, que supuso la consecución, sin duda, del avance en la calidad de la vivienda de promoción pública madrileña a mediados del siglo veinte. Así, la intervención de gestión privada en diferentes instrumentos de desarrollo de iniciativa pública y el impulso normativo hacia cuestiones de calidad exigibles a las necesidades colectivas en materia de vivienda, condicionaron el progreso hacia un nuevo carácter representativo y de satisfacción social de la obra arquitectónica moderna. [12] En la segunda mitad del siglo XX surge, de este modo, un hecho notorio desde la experiencia madrileña: la necesidad obligada de alcanzar y cumplir, en la construcción de viviendas de promoción pública, desde sus diferentes factores de influencia, con exigencias mínimas de calidad técnica como máxima expresión posible, aunque tardía, de una anhelada y racionalizada economía. Se trata de poner en valor un singular y riguroso momento histórico, frente a postulados más actuales de planificación urbana ${ }^{15}$, en el que la importancia de la técnica material se erigió como recurso de gestión de calidad global, regulada desde normativas de exigencia social, y a favor del mejor modelo de vivienda subvencionada posible para el progreso de la ciudad.

[30]
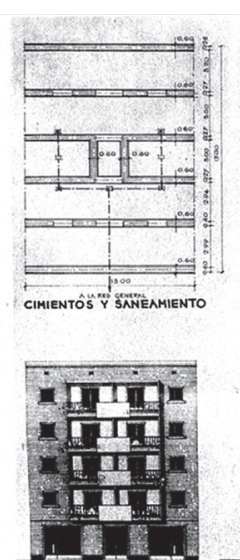

PACHUD PRINCIPN

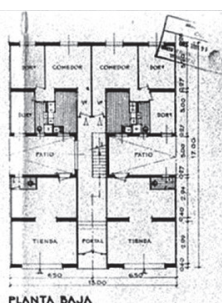

PLANTA BANA

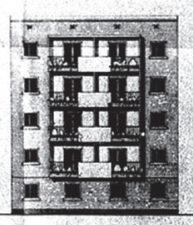

FACHADA POSTERIOR

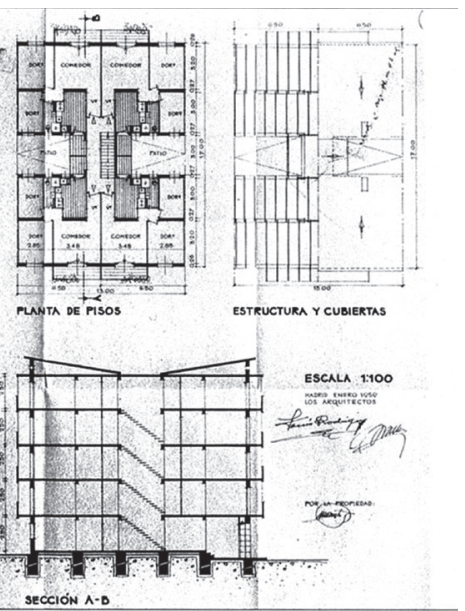

[31]

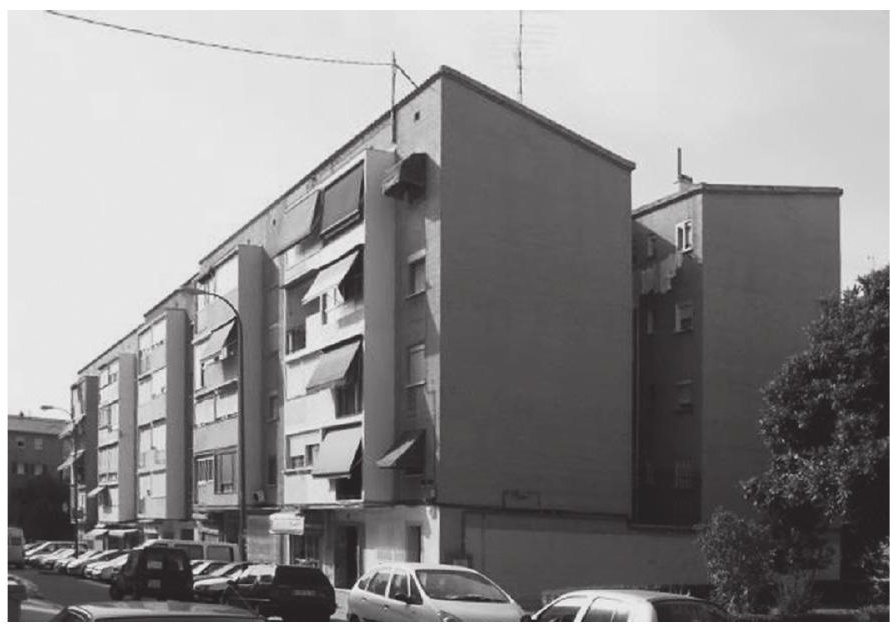

